Vito Fanelli

Peter Spieth

Haibo Zhang

\section{Forced oscillation technique: an alternative tool to define the optimal PEEP?}

Received: 7 March 2011

Accepted: 9 March 2011

Published online: 1 April 2011

C) Copyright jointly held by Springer and ESICM 2011

This editorial refers to the article available at: doi:10.1007/s00134-011-2211-7.

\author{
V. Fanelli · P. Spieth $\cdot$ H. Zhang $(\bowtie)$ \\ Department of Anesthesia, \\ The Keenan Research Centre of the Li Ka Shing Knowledge \\ Institute of St. Michael's Hospital, \\ Room 7-007, Queen Wing, 30 Bond Street, \\ Toronto, ON M5B 1W8, Canada \\ e-mail: zhangh@smh.ca \\ V. Fanelli \\ Department of Anesthesia and Critical Care, \\ Ospedale S. Giovanni Battista-Molinette, University of Turin, \\ Corso Dogliotti 14, 10126 Turin, Italy \\ P. Spieth \\ Department of Anaesthesiology and Intensive Care Medicine, \\ University Hospital Dresden, Dresden, Germany \\ V. Fanelli · P. Spieth · H. Zhang \\ Department of Physiology, Interdepartmental Division of Critical \\ Care Medicine, University of Toronto, Ontario, Canada
}

In the inhomogeneous airspace environment of acute respiratory distress syndrome (ARDS) patients, inappropriate application of tidal volume (VT) and positive endexpiratory pressure (PEEP) has been demonstrated to further worsen lung injury [1-3]. Ventilator-induced lung injury (VILI) may take place at lung volumes that induce over-distention of alveolar units (volutrauma) or cause repeated recruitment and de-recruitment (atelectrauma) $[1,3,4]$. Numerous human and animal studies addressing the mechanisms of VILI culminated in the ARMA trial of the ARDS Network [5], demonstrating that a lung-protective ventilation strategy based on low tidal volume $(6 \mathrm{~mL} / \mathrm{PBW})$ and plateau pressures $\left(P_{\text {plat }}<30 \mathrm{cmH}_{2} \mathrm{O}\right)$ is able to reduce ARDS-associated mortality.

The subsequent attempts to further minimize VILI and improve the prognosis of ARDS patients by using higher PEEP levels have been disappointing in at least three recent clinical trials [6-8] named ALVEOLI, LOVS and EXPRESS, where high versus low PEEP levels were applied in conjunction with low tidal volume ventilation. There may be several reasons to explain the lack of beneficial or even harmful effects of using inappropriate PEEP levels: (1) acute lung injury (ALI)/ARDS patients show great variability of alveolar recruitment in response to PEEP [12]; (2) A fixed combination of $\mathrm{PEEP} / \mathrm{FiO}_{2}$ ratio may have induced alveolar over-distension in some patients [9]; and (3) The use of $P_{\text {plat }}$-guided protective ventilation may not be an appropriate approach because of alterations of transpulmonary pressure due to chest wall impairment [10]. On the other hand, the use of low PEEP levels combined with low tidal volume ventilation has been demonstrated to cause lung injury by repeated alveolar collapse and re-opening [4]. The application of adequate levels of PEEP in the management of ARDS patients remains a critical issue for further investigation [11]. A large portion of potentially recruitable lung units seems to be an independent risk factor for mortality in ARDS [12], thus the benefit of reducing tidal recruitment by increasing PEEP levels may prevail over the effect of increasing alveolar over-distension in this subgroup of patients [13]. A reliable tool at bedside to set desirable PEEP and VT is critical [11]. Traditional methods to tailor and monitor mechanical ventilation such as using pressure-volume curve, static compliance and stress index have shown drawbacks especially when the 
compliance of chest wall is altered. Toward this end, computed tomography (CT) scan is a powerful tool for mapping the distribution of gas volume in the lung compartments under different combinations of PEEP and VT; however, CT scan is yet to be a part of bedside technology.

Forced oscillation technique (FOT) is based on the application of very small lung volume changes with a very short time period (i.e., $0.2 \mathrm{~s}$ for a forcing frequency of $5 \mathrm{~Hz}$ ) in order to measure the oscillatory respiratory system compliance [14]. FOT may offer several potential advantages over traditional methods: (1) it applies very small volume displacement, and minimizes artifacts resulting from non-linearity of the respiratory system; (2) it does not require deep sedation and muscle paralysis; and (3) it can be integrated into currently available ventilator circuits at bedside.

The study by Dellacà and colleagues [15] in the June 2011 issue of Intensive Care Medicine attempted to optimize the level of PEEP by applying FOT in a porcine model of ARDS induced by surfactant depletion. The investigators performed incremental and decremental PEEP trials, and measured both conventional and FOTderived respiratory system compliance at each step of PEEP changes. CT scan analysis was also performed as a gold standard of monitoring lung compartments at end expiration. The used FOT was able to detect the minimal PEEP value to keep the lung open, and this was in good agreement with CT scan analysis with respect to sensitivity and specificity. On the contrary, changes in dynamic compliance and partial pressures of arterial oxygen $\left(\mathrm{PaO}_{2}\right)$ and carbon dioxide $\left(\mathrm{PaCO}_{2}\right)$ were less sensitive compared with FOT. These results suggest that FOT may have potential value to define adequate levels of PEEP to prevent/reduce the occurrence of de-recruitment.

There are some limitations in this study: (1) unlike previous studies $[16,17]$ using a similar model, the authors failed to identify significant hyperinflated area even at high levels of PEEP $\left(\sim 13 \mathrm{cmH}_{2} \mathrm{O}\right)$, which is an important contributor to VILI $[18,19]$. This discrepancy should be addressed in future studies to validate the FOT and CT settings that should be sensitive enough for both de-recruitment and over-distension of alveolar units; (2) The CT scan analysis of the lung compartments was performed at the end expiration; it would be interesting in future studies to compare FOT with CT at the end of the inspiratory phase to detect tidal hyperinflation that can contribute to VILI [18, 19]; and (3) The surfactant depletion model used in this study is not accompanied with abnormal chest wall compliance, so that the validation of FOT to detect the extent of recruitment/derecruitment and hyperinflation remains to be determined in more complicated clinical situations.

In conclusion, the application of FOT appears to be feasible and sensitive to define adequate levels of PEEP in a porcine model of ARDS. Further studies are warranted to determine whether PEEP levels can be individualized to strengthen protective ventilatory strategies by using FOT in preclinical models before clinical studies in humans.

\section{References}

1. Slutsky AS (1999) Lung injury caused by mechanical ventilation. Chest 116:9S-15S

2. Tremblay LN, Slutsky AS (2006) Ventilator-induced lung injury: from the bench to the bedside. Intensive Care Med 32:24-33

3. Lionetti V, Recchia FA, Ranieri VM (2005) Overview of ventilator-induced lung injury mechanisms. Curr Opin Crit Care 11:82-86

4. Muscedere JG, Mullen JB, Gan K, Slutsky AS (1994) Tidal ventilation at low airway pressures can augment lung injury. Am J Respir Crit Care Med 149:1327-1334

5. Acute Respiratory Distress Syndrome Network (2000) Ventilation with lower tidal volumes as compared with traditional tidal volumes for acute lung injury and the acute respiratory distress syndrome. The Acute Respiratory Distress Syndrome Network. N Engl J Med 342:1301-1308
6. Mercat A, Richard JC, Vielle B, Jaber S, Osman D, Diehl JL, Lefrant JY, Prat G, Richecoeur J, Nieszkowska A, Gervais C, Baudot J, Bouadma L, Brochard L (2008) Positive endexpiratory pressure setting in adults with acute lung injury and acute respiratory distress syndrome: a randomized controlled trial. JAMA 299:646-655

7. Meade MO, Cook DJ, Guyatt GH, Slutsky AS, Arabi YM, Cooper DJ, Davies AR, Hand LE, Zhou Q, Thabane L, Austin P, Lapinsky S, Baxter A, Russell J, Skrobik Y, Ronco JJ, Stewart TE (2008) Ventilation strategy using low tidal volumes, recruitment maneuvers, and high positive endexpiratory pressure for acute lung injury and acute respiratory distress syndrome: a randomized controlled trial. JAMA 299:637-645
8. Brower RG, Lanken PN, MacIntyre N, Matthay MA, Morris A, Ancukiewicz M, Schoenfeld D, Thompson BT (2004) Higher versus lower positive endexpiratory pressures in patients with the acute respiratory distress syndrome. N Engl J Med 351:327-336

9. Grasso S, Fanelli V, Cafarelli A, Anaclerio R, Amabile M, Ancona G, Fiore T (2005) Effects of high versus low positive end-expiratory pressures in acute respiratory distress syndrome. Am J Respir Crit Care Med 171:1002-1008

10. Talmor D, Sarge T, Malhotra A, O'Donnell CR, Ritz R, Lisbon A, Novack V, Loring SH (2008)

Mechanical ventilation guided by esophageal pressure in acute lung injury. N Engl J Med 359:2095-2104 
11. Antonelli M, Azoulay E, Bonten M, Chastre J, Citerio G, Conti G, De Backer D, Gerlach H, Hedenstierna G, Joannidis M, Macrae D, Mancebo J, Maggiore SM, Mebazaa A, Preiser JC, Pugin J, Wernerman J, Zhang H (2010) Year in review in Intensive Care Medicine 2010: III. ARDS and ALI, mechanical ventilation, noninvasive ventilation, weaning, endotracheal intubation, lung ultrasound and paediatrics. Intensive Care Med 37:394-410

12. Gattinoni L, Caironi P, Cressoni M, Chiumello D, Ranieri VM, Quintel M, Russo S, Patroniti N, Cornejo R, Bugedo G (2006) Lung recruitment in patients with the acute respiratory distress syndrome. N Engl J Med 354:1775-1786

13. Caironi P, Cressoni M, Chiumello D, Ranieri M, Quintel M, Russo SG, Cornejo R, Bugedo G, Carlesso E, Russo R, Caspani L, Gattinoni L (2010) Lung opening and closing during ventilation of acute respiratory distress syndrome. Am J Respir Crit Care Med 181:578-586
14. Dellaca RL, Andersson Olerud M, Zannin E, Kostic P, Pompilio PP, Hedenstierna G, Pedotti A, Frykholm P (2009) Lung recruitment assessed by total respiratory system input reactance. Intensive Care Med 35:2164-2172

15. Dellacà RL, Zannin E, Kostic $\mathrm{P}$, Andersson Olerud M, Pompilio PP, Hedenstierna G, Pedotti A, Frykholm P (2011) Optimisation of positive endexpiratory pressure by forced oscillation technique in a lavage model of acute lung injury. Intensive Care Med 37:1021-1030. doi: 10.1007/s00134-011-2211-7

16. Carvalho AR, Spieth PM, Pelosi P, Vidal Melo MF, Koch T, Jandre FC, Giannella-Neto A, de Abreu MG (2008) Ability of dynamic airway pressure curve profile and elastance for positive end-expiratory pressure titration. Intensive Care Med 34:2291-2299
17. Grasso S, Stripoli T, Sacchi M, Trerotoli P, Staffieri F, Franchini D, De Monte V, Valentini V, Pugliese P, Crovace A, Driessen B, Fiore T (2009) Inhomogeneity of lung parenchyma during the open lung strategy: a computed tomography scan study. Am J Respir Crit Care Med 180:415-423

18. Grasso S, Stripoli T, De Michele M, Bruno F, Moschetta M, Angelelli G, Munno I, Ruggiero V, Anaclerio R, Cafarelli A, Driessen B, Fiore T (2007) ARDSnet ventilatory protocol and alveolar hyperinflation: role of positive end-expiratory pressure. Am J Respir Crit Care Med 176:761-767

19. Terragni PP, Rosboch G, Tealdi A, Corno E, Menaldo E, Davini O, Gandini G, Herrmann P, Mascia L, Quintel M, Slutsky AS, Gattinoni L, Ranieri VM (2007) Tidal hyperinflation during low tidal volume ventilation in acute respiratory distress syndrome. Am J Respir Crit Care Med 175:160-166 